ARTIGOS

\section{GERENCIAMENTO ALÉM DOS LUCROS: CONTROLE CONTÁBIL EM UMA ENTIDADE SEM FINS LUCRATIVOS}

\section{RESUMO}

Mesmo voltadas para o social, empresas do Terceiro Setor possuem processos que precisam de controle e divulgação a seus diversos interessados, e a contabilidade é uma das ferramentas que contribuem para uma ação positiva perante a sociedade. O objetivo do artigo é identificar se os processos contábeis da entidade estão alinhados às Normas Brasileiras de Contabilidade Aplicadas ao Terceiro Setor - ITG 2002. Foi realizada pesquisa exploratória e descritiva por meio de entrevista semiestruturada com os administradores da organização, além de análise de conteúdo de documentos da organização. Mesmo mencionados como importantes pelos gestores, observou-se que eles não têm conhecimento total sobre as demonstrações contábeis no gerenciamento da entidade. Ficaram evidenciadas inconsistências de algumas operações e uso restrito dos demonstrativos, usados cerimonialmente para exigências legais. Concluiu-se que os relatórios de cunho financeiro são os de maior entendimento dos administradores, enquanto que as demonstrações contábeis se apresentam em um grau de compreensão inferior, sendo relegados, o que implica na falta de utilização da informação contábil no processo de gerenciamento da entidade.

Palavras-chave: Gestão. Demonstrativos Contábeis. Terceiro Setor.

\section{INTRODUÇÃO}

O Terceiro Setor é aquele que agrupa as organizações que, embora prestem serviços de caráter públicos, produzem e comercializam bens e serviços que não são estatais, nem visam lucro econômico como os empreendimentos privados, mas esforçam-se para promover o bem-estar social (MARTINS et al., 2011).

O surgimento das organizações do Terceiro Setor se deu após a segunda grande guerra, quando o mundo enfrentou vários problemas de cunho social, de forma que Governos não conseguiam atender às necessidades coletivas. Essas organizações surgiram como instituições assistencialistas, ligadas a grupos religiosos. No Brasil, a incidência dessas organizações ganhou força 
na década de 1990, mas há relatos de que nas décadas de 1970 e 1980 já havia movimentos de organizações assistencialistas. Suas raízes encontram-se na Igreja Católica Apostólica Romana, porta-voz de problemas como a repressão, desigualdade e injustiça social. Em 1978 o conceito de cidadania foi definido, facilitando a elaboração de políticas sociais, culminando 20 anos depois com a Lei 9790/99, que criou as Organizações da Sociedade Civil de Interesse Público (OSCIPs) (FERNANDES, 1994; FAGUNDES; RODRIGUES, 2017).

Essas organizações não são diferentes das entidades privadas, pois precisam de organização contábil para realizar seus registros e controles (SILVA et al., 2006). Por sua necessidade, a contabilidade desenvolve um importante papel de auxiliar e demonstrar para a sociedade o trabalho que realmente vem sendo desenvolvido por parte dessas instituições sem finalidade de lucro (MARTINS et al., 2011). O Terceiro Setor é caracterizado como um "meio termo" do ambiente político-econômico, intermediando as relações entre o Estado e o mercado no que tange às questões da melhoria social (CAMARGO, 2001). O termo “Terceiro Setor" surgiu na década de 1970, nos Estados Unidos, para designar organizações sem finalidades lucrativas, não pertencentes nem ao setor privado, nem ao setor público. Esse setor engloba vários tipos de organizações sem fins lucrativos e, no Brasil, uma das principais formas de atuação desse setor é composto pelas Organizações Não-Governamentais (MAÑAS; MEDEIROS, 2012).

O Terceiro Setor tem sido definido de diversas maneiras; internacionalmente é conceituado como o conjunto de organizações privadas, sem finalidade lucrativa, que atendem às finalidades tanto coletivas, quanto públicas. No Brasil, o Terceiro Setor tem sido relacionado como ação social pri- vada, fortemente a associado às organizações não-governamentais (ONGS) e às entidades filantrópicas e assistenciais, assim como as ações de responsabilidade social das empresas privadas. Esses termos, acabam por representar identidades compartilhadas de grupos similares de organizações (FALCONER; VILELA, 2001).

Entre estas terminologias, a mais utilizada é a de entidade sem finalidade de lucros, de acordo com a ITG 2002, do Conselho Federal de Contabilidade que abrange diversas naturezas jurídicas que não visam à lucratividade e estabelecem critérios e procedimentos específicos de avaliação, de reconhecimento das transações e variações patrimoniais.

Mesmo com a visão voltada para o social, o Terceiro Setor também possui um processo econômico que precisa ser controlado, e a contabilidade é um dos instrumentos que contribuem para construção de uma ação positiva perante a sociedade; por essa razão, o presente artigo busca conhecer como essas entidades se mantêm e como são feitos seus registros, seu controle e a prestação de contas de seus recursos, analisando a situação de uma instituição, como caso. Assim, considerando a importância da divulgação de informações com qualidade por parte das entidades do Terceiro Setor, a pesquisa ocupa-se da seguinte questão: Como as informações contábeis são utilizadas na gestão de uma entidade do Terceiro Setor?

Objetiva-se identificar se os processos contábeis da entidade estão alinhados às Normas Brasileiras de Contabilidade Aplicadas ao Terceiro Setor - ITG 2002. Em termos práticos, busca-se identificar como uma entidade do Terceiro Setor se utiliza das demonstrações contábeis no processo de gestão.

Este estudo busca fornecer insights tanto à pesquisa acadêmica, aos profissionais da área, assim como auxiliar os leitores a melhor 
compreender as entidades sem fins lucrativos, implicando na forma de como conduzir sua gestão, podendo-se expandir para um número maior de municípios em que se identifiquem organizações similares, contribuindo, assim, com a disponibilização de informações que levem a seus gestores e à sociedade, informações sobre a gestão dessas entidades.

\section{REFERENCIAL TEÓRICO}

A literatura aponta que o uso de relatórios contábeis e financeiros servem de instrumentos de comunicação entre as organizações do Terceiro Setor e suas partes interessadas (stakeholders). No entanto, poucas divulgavam seus relatórios financeiros, composição e gestão dos recursos recebidos. Outro ponto a ser destacado diz respeito à qualidade das informações contábeis para essas entidades, que ainda são pouco exploradas, uma vez que os aspectos regulamentadores e de evidenciação ainda são precários (FALCONER; VILELA, 2001; BEUREN; CORREAA, 2009; CRUZ, 2010; FAGUNDES; RODRIGUES, 2017).

Porém, não basta apenas divulgar as informações; as organizações também devem se utilizar dos relatórios financeiros para amparar as suas decisões, uma vez que a divulgação de informações desencontradas pode levar a uma redução da confiança entre a organização e seus diversos stakeholders (CAMARGO, 2001; SANTOS, 2000). No Brasil, o índice de divulgação das informações financeiras das organizações do Terceiro Setor é considerado baixo (MILANI FILHO, 2011; GOLLO; SCHULZ; ROSA, 2014).

A regulação e o gerenciamento das entidades do Terceiro Setor podem ser afetadas por alguns fatores: (i) pelo relacionamento entre as entidades e seus stakeholders (normalmente os doadores e o Estado); (ii) pelo mercado, na forma como as organizações conseguem acesso aos recursos; e, (iii) por suas características internas, como a capacidade institucional do Terceiro Setor, suas normas e busca por legitimidade (BIES, 2010).
Com base nesses pressupostos, um olhar sob a perspectiva da Teoria da Agência contribui para entender o gerenciamento da associação, focando no relacionamento entre o principal e o agente. Nesse relacionamento, o principal delega o trabalho ao agente e o monitora para garantir o cumprimento dos deveres atribuídos (EISENHARDT, 1985). Para o caso em análise, o Estado seria visto como o principal, tendo maior relevância; e a Associação como o agente. Ainda assim, a literatura de agência traz diversos exemplos de como a teoria está relacionada ao mundo corporativo, não havendo muitos trabalhos relacionados ao Terceiro Setor. Nesse sentido, Fama e Michael (1983) fornecem uma ilustração útil: na ausência de proprietários formais, em organizações sem fins lucrativos os proprietários podem ser definidos como doadores; então, seria papel dos conselhos (atuando como diretores) proteger e administrar os investimentos dos doadores por meio do monitoramento, do gerenciamento do pessoal e do cumprimento dos demais papéis gerenciais, controlando os "agentes".

Sob um olhar da Teoria da Dependência de Recursos, segundo fator definido por Bies (2010), as organizações buscam recursos necessários para sua sobrevivência e, portanto, devem estimular interações e trocas com outras pessoas possuidoras de recursos no ambiente em seu redor que possam transferi-los para as organizações, a fim de garantir suas atividades (PFEFFER; SALANCIK, 1978 apud BIES, 2010). Para o caso em estudo, as instituições desenvolveriam estratégias junto às organizações públicas e privadas para que pudessem vir a financiar suas atividades de diversas maneiras.

Analisando as características do setor em estudo, pode ser possível analisar as pressões sofridas pelas entidades do Terceiro Setor para garantir a legitimidade de suas ações no cumprimento de normas e regulamentos estabelecidos por organismos externos. Essas relações podem ser úteis para entender como essas entidades respondem às influências externas, de forma a cumprir com diretrizes institucionais, copiando as respostas de outras organizações 
similares, ou respondendo de acordo com as normas e rituais institucionalizados (DiMAGGIO; POWELL, 1983). No caso em questão, haveria a necessidade de cumprimento de normas legais e do cumprimento de prestação de contas para órgãos específicos, podendo ainda, a associação ser orientada para o cumprimento de padrões estabelecidos pelo agrupamento de associações ligadas ao Terceiro Setor.

Estudos internacionais sobre as entidades inseridas no Terceiro Setor abordam, entre outros, a accountability como instrumento de transformação e engajamento com a sociedade em que estão inseridas. Em um cenário provido de mudanças, palavras como accountability e gerenciamento por desempenho proliferaram em discussões e documentos, apesar do fato de que esses termos serem bastante difíceis de definir e operacionalizar de qualquer maneira (HYNDMAN; McKILLOP, 2018).

McConville e Cordery (2018) realizaram um estudo com o objetivo de entender como diferentes jurisdições têm respondido às chamadas para aumentar a performance da accountability em instituições de caridade, por meio de um estudo exploratório, utilizando benchmarking em quatro jurisdições: Austrália, Nova Zelândia, Reino Unido e Estados Unidos.

Yang e Northcott (2018) realizaram pesquisa que analisou o trabalho institucional feito por pessoas que trabalham em instituições de caridade como forma de direcionar as práticas de mensuração de resultados. O conceito de trabalho institucional de acordo com Lawrence, Suddaby e Leca (2009) destaca como os atores dentro das instituições direcionam seus esforços de trabalho para mudar ou manter normas e práticas, esclarecendo como esses mesmos atores propositalmente (re)moldam práticas institucionalizadas (p.e. prestação de contas aos agentes financiadores dessas instituições, engajamento da comunidade com seus beneficiários, entre outros), para efetivar a accountability. No estudo em questão, o trabalho realizado pelos representantes das instituições do Terceiro Setor em relação à prestação de contas moldaria o accountability percebido e poderiam aumentar o engajamento da comunidade em que atuam.

\section{METODOLOGIA}

A metodologia utilizada na pesquisa é de um estudo de caso único, de caráter exploratório (BRYMAN, 2012). A pesquisa exploratória possui como objetivo proporcionar maior familiaridade com o problema, para torná-lo mais explícito (SILVA, 2003; BEUREN, 2006). Esse tipo de estudo foi escolhido por conveniência dada a facilidade dos pesquisadores para condução da coleta de dados e entrevistas com os representantes da entidade. O município possui população estimada de 84.014 habitantes (IBGE, 2018) e 345 organizações da sociedade civil, segundo levantamento do IPEA(2018), que, em sua grande maioria, são organizações religiosas, e apenas uma instituição de acolhimento educacional a pessoas com necessidades especiais, o que justifica a escolha da instituição.

No que diz respeito aos procedimentos técnicos, o estudo se utiliza de pesquisa documental valendo-se de toda a sorte de documentos para conhecer melhor o fenômeno estudado (CRESWELL, 2007). Como o foco, o estudo está limitado ao exercício de 2015, não sendo analisados os exercícios anteriores.

Buscou-se, inicialmente, contato por telefone com os responsáveis pela entidade, foram expostos os objetivos do trabalho e a necessidade de colher dados junto à entidade, para realização do presente estudo. Para a realização da coleta de dados utilizou-se um questionário estruturado com perguntas fechadas e abertas, aplicada aos gestores da entidade. Utilizado como protocolo de pesquisa, o questionário foi dividido nos seguintes tópicos: (i) informações gerais da entidade; (ii) perfil da organização; (iii) perfil dos dirigentes; (iv) processo de comunicação com usuários internos e externos; (v) gestão e relatórios financeiros.

Foram realizadas também entrevistas semiestruturadas com a finalidade de realizar interpretação e análise de dados utilizando descrições e narrativas (TRIVIÑOS, 1987). Esse método mostrou-se mais adequado, pois deixa os entrevistados livres falar de acordo com a flexibilidade em alguns pontos, de forma a buscar mais 
evidências válidas e entendimento sobre os fatos (YIN, 2003; EASTERBY-SMITH; THORPE; JACKSON, 2008). As entrevistas foram realizadas com a presidente e diretora financeira da entidade, em dois encontros, durante os meses de maio e junho de 2016 e tiveram duração entre 15 a 26 minutos, com o intuito de buscar melhor compreensão sobre percepção delas quanto a utilização das informações e relatórios contábeis no processo de gestão da entidade.

Os dados contábeis como Balanço Patrimonial e Demonstração do Resultado do Exercício foram disponibilizados pelo escritório de contábil que presta serviço à entidade. As demais informações financeiras, como movimento de caixa e controle de contas a pagar e receber, foram disponibilizados pelas gestoras da instituição. O foco do estudo está limitado ao exercício de 2015, não sendo analisados os exercícios anteriores.

Nos aspectos relacionados à gestão da APAE, inicialmente buscou-se delinear o perfil dos seus dirigentes. Em seguida, com base nos documentos disponibilizados pela entidade, foram identificados os tipos de recursos com os quais a instituição se mantém para, num terceiro momento, discutir os aspectos ligados à contabilidade, por meio da análise das demonstrações contábeis disponibilizadas pelo escritório contábil. Também foi analisado o nível de conhecimento que os gestores têm sobre os relatórios financeiros, quais são utilizados no seu dia a dia e quais são utilizados para a tomada de decisão e como são feitos os registros contábeis e a prestação de contas de seus recursos.

\section{A ENTIDADE}

O estudo de caso ocorreu na Associação de Pais e Amigos dos Excepcionais - APAE, entidade privada sem fins lucrativos e econômicos de cunho filantrópico, localizada no município de Guanambi. A entidade foi criada em $1^{\circ}$ de outubro de 1987 por um grupo de pais, autoridades e pessoas da sociedade, possuindo como objeto social o caráter assistencial, educacional, de saúde, cultural, de estudo e pesqui- sa, entre outros, com atuação preponderante na política de assistencial social, atuando de forma complementar com políticas de educação e de saúde. Tem como objetivo principal atender pessoas com necessidades especiais de ordem intelectual e múltipla para habilitação ou reabilitação, bem como promover a autonomia, melhoria da qualidade de vida, defesa e garantia de seus direitos. No período do levantamento dos dados desta pesquisa, a entidade atendia cerca de 100 alunos com deficiência intelectual.

Os serviços prestados são de proteção social especial de média e/ou alta complexidade e os atendimentos são voltados às famílias e pessoas com deficiência em situação de vulnerabilidade ou risco social e pessoal. A instituição possui autonomia administrativa e financeira, tendo sede própria, composta por dois pavilhões sendo uma parte administrativa (recepção, secretaria, diretoria, psicologia, assistência social, fisioterapia, almoxarifado, quatro banheiros) e outra área pedagógica (cinco salas de aula, um auditório, uma sala de coordenação, um refeitório, um almoxarifado, cinco banheiros). A escola dispõe ainda de um pátio, uma piscina e uma quadra poliesportiva, onde atualmente atende 109 pessoas com necessidades especiais nas áreas clínicas e pedagógicas de 0 a 50 anos.

Em observância ao Estatuto padronizado das APAE do Brasil, a entidade possui órgãos responsáveis pela administração: Assembleia Geral, Conselho de Administração; Conselho Fiscal; Diretoria Executiva; Consultor Jurídico; Conselho Consultivo. AAssembleia Geral é o órgão soberano das APAE e sua Diretoria Executiva é composta pelo Presidente, Vice-Presidente, $1^{\circ}$ Diretor Financeiro, $2^{\circ}$ Diretor Financeiro, $1^{\circ}$ Diretor Secretário, $2^{\circ}$ Diretor Secretário, Diretor Social, Diretor do Patrimônio. De acordo com o estatuto, a APAE não remunera nem distribui lucros ou dividendos aos seus associados, dirigentes ou conselheiros e se houver um eventual superávit, o mesmo será investido nas atividades e propósitos da instituição.

A entidade possui 11 colaboradores entre contratados e cedidos pelo Estado e Município e, além da Diretoria Executiva, existem profis- 
sionais responsáveis pela área pedagógica e clínica e área administrativa que administram os projetos e programas desenvolvidos.

A APAE se mantém por meio de benefício de prestação continuada mediante convênios com o Estado da Bahia, por meio da Secretaria Estadual da Assistência e do Desenvolvimento Social e com a Prefeitura Municipal de Guanambi, pelo Fundo do Conselho Municipal de Assistência Social. A APAE também recebe contribuição de seus associados, serviços voluntários do Juizado Especial Criminal da Comarca de Guanambi, por meio de cessão de mão de obra carcerária, parceria com algumas empresas privadas com doações de aportes financeiros e com algumas instituições de ensino público e privados da cidade que fornecem estagiários na área de Enfermagem, Serviço Social, Psicologia, Nutrição e Biomedicina, por meio das vagas oferecidas pela APAE.

\section{RESULTADOS E DISCUSSÕES}

\subsection{ASPECTOS RELACIONADOS À GESTÃO DA ENTIDADE}

Verificou-se que a APAE é gerida por uma diretora que possui formação no ensino superior em Psicologia e Psicopedagogia e, dedica em média 30 horas semanais de atividades na instituição. Em relação ao quantitativo de funcionários, a instituição possui 11 funcionários, sendo 6 professores, 1 merendeira, 1 auxiliar de serviços gerais, 1 secretária, 1 diretora e 1 vigia. Vale ressaltar que desses funcionários 4 professores são cedidos pelo Governo Estadual e 2 pela Prefeitura Municipal e os demais são mantidos através de recursos próprios.

$\mathrm{Na}$ sequência, demonstram-se as fontes de recursos financeiros da instituição, sua aplicação e aspectos relacionados aos relatórios e a demonstrações contábeis.

Ao analisar o quadro abaixo, observa-se que a maior parte dos recursos é recebido do Setor Público, e já tem aplicação específica; devido a isso, existe uma rigidez em sua destinação, não podendo ser usados livremente para atender às diversas necessidades do dia a dia da entidade de maneira flexível, o que dificulta a gestão em termos da necessidade de suprir emergências que possam surgir ao longo do ano.

\begin{tabular}{|l|l|}
\hline \multicolumn{1}{|c|}{ Fonte dos recursos } & \multicolumn{1}{c|}{$\begin{array}{c}\text { recursos } \\
\mathbf{2 0 1 5}\end{array}$} \\
\hline 1. Própria (recursos decorrentes de prestação de serviços da entidade) & $0,0 \%$ \\
\hline 2. Própria (recursos decorrentes de mensalidades / doações dos membros ou associados) & $12,65 \%$ \\
\hline $\begin{array}{l}\text { 3. Privada (recursos decorrentes doações e parcerias com empresas e entidades privadas) } \\
\text { 4. Privada (recursos de doações eventuais) }\end{array}$ & $10,56 \%$ \\
\hline $\begin{array}{l}\text { 5. Pública (recursos de subvenções, convênios e parcerias com órgãos ou entidades } \\
\text { públicas) }\end{array}$ & $66,33 \%$ \\
\hline 6. Internacional Privada (recursos de entidades e organizações internacionais) & $0,0 \%$ \\
\hline 7. Internacional Pública (recursos de Países estrangeiros, ONU, etc.) & $0,0 \%$ \\
\hline 8. Outros. (Receita de aluguel) & $7,92 \%$ \\
\hline Total & $100 \%$ \\
\hline
\end{tabular}

Quadro 1 - Proporção da origem dos recursos financeiros recebidos na organização Fonte: dados da pesquisa (2016). 
Em entrevista, quando questionados acerca dos instrumentos utilizados para gestão da organização, os gestores informaram que possuem conhecimento dos relatórios: Conta a Pagar; Balanço Patrimonial; extrato bancário e Demonstração do Resultado do Período. Para a realização das atividades correntes foram informados o uso dos relatórios de Conta a Pagar e Extrato bancário. Os relatórios utilizados para tomada de decisão são: Balanço Patrimonial e Demonstração do Resultado do Período (relacionando à Demonstração de Superávit ou Déficit do Exercício).

Apesar do mencionado pelos gestores, observou-se que eles não têm conhecimento total sobre as demonstrações contábeis no gerenciamento da entidade. Ademais, os gestores só recebem da contabilidade a Demonstração do Resultado do Período e Balanço Patrimonial, havendo, dessa forma uma falta de adequação às Normas do Terceiro Setor pela incompletude de demonstrações, como pela falta de conhecimento da Demonstração da Mutação do Patrimônio Líquido e Demonstração de Fluxo de Caixa. ceiro e dos fluxos de caixa da entidade, de maneira que essas informações sejam úteis a um grande número de usuários em suas avaliações e tomadas de decisões econômicas sobre alocação de recursos.

Por não ser obrigatório, não há divulgação dos relatórios financeiros para a sociedade. Assim, pode-se inferir que as informações que poderiam ser de interesse não só aos membros e integrantes da associação, mas como também a sociedade, não são repassadas, dificultando assim o conhecimento da real situação financeira da entidade, confirmando o resultado divulgado por Falconer e Vilela (2001) e outras pesquisas da área, desta forma, prejudica a relação com a sociedade, que não está somente relacionada à ação social desenvolvida, mas na prestação de contas da origem e destino dos recursos utilizados e dos resultados alcançados (RESENDE, 2006).

\begin{tabular}{|l|c|c|c|}
\hline \multicolumn{1}{|c|}{ RELATÓRIOS } & $\begin{array}{c}\text { Relatórios de que } \\
\text { os diretores têm } \\
\text { conhecimento }\end{array}$ & $\begin{array}{c}\text { Relatórios utilizados } \\
\text { no seu dia-a-dia }\end{array}$ & $\begin{array}{c}\text { Relatórios para } \\
\text { tomada de decisão }\end{array}$ \\
\hline Movimento caixa & & $\mathrm{X}$ & \\
\hline Relatórios de contas a pagar & $\mathrm{X}$ & & \\
\hline Balanço patrimonial & & & \\
\hline $\begin{array}{l}\text { Demonstração das mutações do patrimônio } \\
\text { social }\end{array}$ & & $\mathrm{X}$ & \\
\hline Demonstração do fluxo de caixa & $\mathrm{X}$ & & $\mathrm{X}$ \\
\hline Extrato bancário & $\mathrm{X}$ & & \\
\hline Balancete & & & \\
\hline Demonstração do Resultado do Período & & & \\
\hline
\end{tabular}

Quadro 2 - Relatórios utilizados pela entidade Fonte: dados da pesquisa (2016).

Bulgarim et al. (2011) afirmam que as demonstrações contábeis são uma representação estruturada da posição patrimonial, financeira e do desempenho financeiro de uma entidade. O objetivo das demonstrações contábeis destinadas a atender propostas gerais é o de proporcionar informações acerca da posição patrimonial e financeira, do desempenho finan-

\subsection{ANÁLISES DOS LANÇAMENTOS CONTÁBEIS DA APAE DE GUA- NAMBI}

Essa parte da análise teve como base os demonstrativos contábeis e fiscais disponibilizados pela entidade de forma a melhor identificar o seu modus operandi com referência ao 
exercício social de 2015. A entidade mantém sua escrituração contábil através escritório de contabilidade terceirizado, que realiza registros das suas operações.

A contabilidade das entidades sem fins lucrativos difere em alguns pontos da contabilidade societária. Por meio do Balanço Patrimonial e da Demonstração do Resultado do Período (relacionando à Demonstração de Superávit ou Déficit do Exercício) referente ao exercício de 2015 foram analisadas as seguintes operações neste estudo de caso: Receitas de Doações em espécie, Trabalho Voluntário e o registro da Depreciação.

Para a verificação dos dados contábeis da entidade, evidenciação e reconhecimento das transações, foram utilizados como parâme- tro, o Manual de Procedimentos para o Terceiro Setor, publicado pelo Conselho Federal de Contabilidade (2015), a Resolução CFC N ${ }^{\circ}$ 1.409/12 que aprovou a Interpretação Técnica Geral (ITG) 2002 R1 - Entidade sem Finalidade de Lucros, em sua primeira revisão e o Caderno de Procedimentos Aplicáveis à Prestação de Contas das Entidades do Terceiro Setor (Fundações) publicado em 2011.

Ao analisar a Demonstração de Superávit ou Déficit do Exercício (informada como Demonstração do Resultado do Período pelo escritório de contabilidade) percebeu-se que a APAE de Guanambi não está em conformidade com a normativa quanto ao registro de lançamentos de algumas doações, as quais seguem transcritas abaixo:

\begin{tabular}{|l|r|}
\hline \multicolumn{2}{|c|}{ DEMONSTRAÇÃO DO RESULTADO DO PERÍODO - ANO: 2015 } \\
\hline RECEITA OPERACIONAL BRUTA & \\
\hline Verbas e Subvenções & $\mathbf{6 9 . 8 5 8 , 1 0}$ \\
\hline Convênio CNAS Área da Assistência Social & $57.764,82$ \\
\hline Programa APAE Energia Área da assistência Social & $9.598,28$ \\
\hline Convênio Teste do Pesinho Área de Saúde & $2.495,00$ \\
\hline OUTRAS RECEITAS & $\mathbf{2 1 . 0 0 5 , 0 0}$ \\
\hline Receitas de Doações Área da Educação & $2.306,82$ \\
\hline Recitas de aluguel Área de Educação & $7.200,00$ \\
\hline Outras Receitas Área da Educação & $11.498,18$ \\
\hline RECEITA OPERACIONAL LÍQUIDA & $\mathbf{9 0 . 8 6 3 , 1 0}$ \\
\hline (-) Despesas c/ o Pessoal Área da Assistência Social & $27.423,19$ \\
\hline (-) Despesas c/ o Pessoal área da Educação & $13.944,36$ \\
\hline (-) Despesas c/ o Pessoal Área da Saúde & $5.110,05$ \\
\hline (-) Despesa Geral na Área da Assistência Social & $59.187,75$ \\
\hline (-) Despesa Geral na Área da Educação & $2.165,27$ \\
\hline (-) Despesas Geral na Área da Saúde & 433,05 \\
\hline DÉFICIT LÍQUIDO DO EXERCÍCIO & $\mathbf{( 1 7 . 4 0 0 , 5 7 )}$ \\
\hline
\end{tabular}

Quadro 3 - Demonstração do Resultado do Período

Fonte: dados da pesquisa (2016). 


\begin{tabular}{|c|c|c|c|}
\hline \multicolumn{2}{|l|}{ ATIVO } & \multicolumn{2}{|l|}{ PASSIVO } \\
\hline ATIVO CIRCULANTE & $R \$ 2.238,48$ & PASSIVO CIRCULANTE & R\$ $1.717,84$ \\
\hline \multicolumn{2}{|l|}{ DISPONIBILIDADES } & \multicolumn{2}{|c|}{ OBRIG. SOCIAIS E TRABALHISTAS } \\
\hline \multicolumn{2}{|l|}{ Caixa Geral } & INSS a Recolher & $\mathrm{R} \$ 126,08$ \\
\hline Caixa Área da Assistência Social & $\mathrm{R} \$ 947,68$ & FGTS a Recolher & $\mathrm{R} \$ 126,08$ \\
\hline \multicolumn{2}{|l|}{ Banco Conta Aplicação } & PIS s/ Faturamento & $\mathrm{R} \$ 15,76$ \\
\hline Banco Área da Assistência Social & $\mathrm{R} \$ 1.290,80$ & Salários a Pagar & $\mathrm{R} \$ 1.449,92$ \\
\hline NÃO CIRCULANTE & R\$ 247.027,26 & NÃO CIRCULANTE & R\$ 17.013,78 \\
\hline \multicolumn{2}{|l|}{ Subvenção Geral a receber } & \multicolumn{2}{|c|}{ SUBVENÇÕES PÚBLICAS A REALIZAR } \\
\hline \multicolumn{2}{|l|}{$\begin{array}{l}\text { Sub. a Receber na Área da Assistência } \\
\text { Social }\end{array}$} & \multicolumn{2}{|c|}{$\begin{array}{l}\text { Sub. a realizar na área da } \\
\text { Assist. Social }\end{array}$} \\
\hline IMOBILIZADO & $\mathrm{R} \$ 230.013,48$ & & \\
\hline Imobilizado Área da Administração & $\mathrm{R} \$ 80.504,72$ & & \\
\hline Edificação & $\mathrm{R} \$ 79.619,17$ & & \\
\hline \multirow{2}{*}{$\begin{array}{l}\text { Móveis e Utensílios } \\
\text { Imobilizado Área da Saúde }\end{array}$} & $\mathrm{R} \$ 885,55$ & & \\
\hline & $\mathrm{R} \$ 3.450,20$ & & \\
\hline Móveis e Utensílios & $\mathrm{R} \$ 1.278,30$ & $\begin{array}{l}\text { PATRIMÔNIO } \\
\text { LÍQUIDO }\end{array}$ & R\$ 175.632,75 \\
\hline Aparelhos e Equipamentos & $\mathrm{R} \$ 2.171,90$ & Patrimônio Social & $\mathrm{R} \$ 205.535,99$ \\
\hline $\begin{array}{l}\text { Imobilizado Área da Assistência } \\
\text { Social }\end{array}$ & $\mathrm{R} \$ 137.088,03$ & Déficit do Exercício & $16.882,57)^{(\mathrm{R} \$}$ \\
\hline Móveis e Utensílios & $\mathrm{R} \$ 3.048,73$ & Déficit Acumulado & $(\mathrm{R} \$ 13.020,67)$ \\
\hline Aparelhos e Equipamentos & $\mathrm{R} \$ 16.039,30$ & & \\
\hline Veículos e Utilitários & $\mathrm{R} \$ 118.000,00$ & & \\
\hline Imobilizado Área da Educação & $\mathrm{R} \$ 8.970,53$ & & \\
\hline Móveis e Utensílios & $\mathrm{R} \$ 738,27$ & & \\
\hline Aparelhos e Equipamentos & $\mathrm{R} \$ 8.232,26$ & & \\
\hline \multicolumn{2}{|l|}{ Depreciação Acumuladas } & & \\
\hline (-) Depreciações Acumuladas & $(\mathrm{R} \$ 54.901,37)$ & & \\
\hline TOTAL DO ATIVO & $\mathrm{R} \$ \mathbf{1 9 4 . 3 6 4 , 3 7}$ & TOTAL DO PASSIVO & R\$ 194.364,37 \\
\hline
\end{tabular}

Quadro 4 - Balanço Patrimonial: ano 2015

Fonte: dados da pesquisa (2016).

\subsubsection{Receitas de Doações}

Bulgarim et al. (2011) caracterizam que receitas como aumentos dos benefícios econômicos durante o período contábil sob a forma de entrada de novos recursos ou aumento de ativos ou diminuição de passivos que resultem em aumento do patrimônio líquido (social) e que não sejam provenientes de aporte dos associados da entidade. As doações são, a principal fonte de recursos para o sustento das princi- pais atividades das entidades do Terceiro Setor, podendo ocorrer em moeda corrente, gêneros alimentícios, equipamentos ou por meio do recebimento de prestação de serviços voluntários (FRANÇA, 2015).

As doações podem ser recebidas para custeio ou investimento. Em quaisquer das formas as doações podem se dar in natura ou em espécie. Quando in natura os bens doados 
podem ter valor declarado ou não. Se o doador optar por não declarar o valor do bem doado, é necessário que a entidade estime o valor com base nos preços médios cobrados pelo mercado; dessa forma, se a entidade recebe arroz, feijão, farinha e óleo comestível, por exemplo, deve valorar as quantidades recebidas pelo valor que esta desembolsaria se fizesse a aquisição no mercado. O modo mais objetivo de obter os preços é por meio de pesquisa em mercado local dos bens recebidos e produzir documento hábil para o registro. No estudo de caso, foram identificados que a entidade recebeu diversos alimentos doados pela Prefeitura Municipal; no entanto, não foram feitas as avaliações e registros dessas doações recebidas. Por meio do levantamento dos gêneros alimentícios recebidos, foi feita uma simulação dos valores com base nos valores mais atuais dos elementos recebidos e elaborado uma tabela conforme demonstrado no quadro 5.

\begin{tabular}{|l|r|r|r|}
\hline \multicolumn{1}{|c|}{ Produtos recebidos } & Quantidade & Parâmetro unitário & \multicolumn{1}{c|}{ Valor estimado } \\
\hline Feijão mulatinho & $100 \mathrm{~kg}$ & 3,80 & 380,00 \\
\hline Arroz tipo 1 & $100 \mathrm{~kg}$ & 5,50 & 550,00 \\
\hline Farinha & $10 \mathrm{cx}$ & 2,00 & 20,00 \\
\hline Óleo de soja & $20 \mathrm{lt}$ & 4,50 & 90,00 \\
\hline Tomate & $60 \mathrm{~kg}$ & 7,00 & 420,00 \\
\hline Frango congelado & $20 \mathrm{~kg}$ & 5,70 & 114,00 \\
\hline \multicolumn{2}{|c|}{ Valor total das doações } \\
\hline
\end{tabular}

Quadro 5 - Mensuração de doação de gêneros alimentícios recebidos

Fonte: dados da pesquisa (2016).

O reconhecimento contábil deve ser procedido nas rubricas específicas de cada natureza de bem, utilizando a titulação e função adequada de cada conta. Nesse caso, as contas de aplicação são também contas de despesas, pois a finalidade é o custeio no consumo imediato. Para o caso em estudo, conforme relatado pela gestora da entidade, todos os alimentos recebidos são consumidos de imediato; dessa forma, os registros contábeis seriam processados conforme demonstrado no Quadro 6.

\begin{tabular}{|l|c|c|c|}
\hline \multicolumn{1}{|c|}{ Título da Conta } & Débito & Crédito & Histórico \\
\hline Despesa suprimento alimentação & $1.574,00$ & & Doação de alimentos \\
\hline Receita de doação & & $1.574,00$ & Doação de alimentos \\
\hline Valor total das doações & $\mathbf{1 . 5 7 4 , 0 0}$ & $\mathbf{1 . 5 7 4 , 0 0}$ & \\
\hline
\end{tabular}

Quadro 6 - Reconhecimento contábil simultâneo da despesa e da receita

Fonte: dados da pesquisa (2016).

\subsubsection{Contabilização de serviços voluntários}

As organizações sem fins lucrativos utilizam o serviço voluntário para contribuir no desenvolvimento de sua missão e nas atividades desenvolvidas e esses serviços representam recursos utilizados pelas organizações e representam valores econômicos que devem ser reconhecidos (FRANÇA, 2015).

A APAE de Guanambi recebeu esse tipo de doação, mas não evidenciou em seus demonstrativos os casos de serviços voluntários recebidos no exercício de 2015. A falta de controle dos serviços voluntários recebidos em doação acarreta perda de informação na elaboração das demonstrações, o que prejudica a evidenciação da dimensão desses trabalhos para a entidade. Por 
entrevista, foram relatadas algumas ações de voluntários na entidade e que serão demonstrados nos quadros 7 e 8 por simulação de como eles deveriam ser mensurados e contabilizados.

\begin{tabular}{|c|c|c|c|}
\hline Serviço voluntário & Unidade de tempo & Parâmetro unitário & Valor estimado \\
\hline Serviço de pedreiro & 100 horas & 15,00 & $1.500,00$ \\
\hline Serviço de servente & 100 horas & 7,00 & 700,00 \\
\hline Valor total das doações & & & $2.200,00$ \\
\hline
\end{tabular}

Quadro 7 - Mensuração do trabalho voluntário

Fonte: dados da pesquisa (2016).

\begin{tabular}{|c|c|c|c|}
\hline Título da Conta & Débito & Crédito & Histórico \\
\hline Despesas com Serviço Pedreiro & $2.200,00$ & & Trabalho voluntário \\
\hline Receita com Trabalho Voluntário & & $2.200,00$ & Trabalho voluntário \\
\hline Valor total das doações & $2.200,00$ & $2.200,00$ & \\
\hline
\end{tabular}

Quadro 8 - Reconhecimento contábil do trabalho voluntário

Fonte: dados da pesquisa (2016).

Qualquer que seja o parâmetro para quantificação do valor financeiro, deve ser utilizado o valor que seria pago se o trabalho fosse remunerado, devendo refletir o valor justo, pois esse seria o valor a despendido para obtenção dos serviços. Com esse procedimento, a entidade registra, simultaneamente, a aplicação na despesa de custeio de uma fonte de receita de trabalho voluntário, procedendo, desta forma, de acordo com o item 19 da ITG 2002 (R1).

Pelo relato dos gestores, a mão de obra voluntária é fundamental para o funcionamento da entidade e a mensuração, registro e evidenciação demonstram para os gestores, doadores financeiros, governos, os próprios voluntários e toda a sociedade o impacto financeiro e importância do voluntariado para a entidade.

\subsubsection{Contabilização de Depreciação}

A depreciação corresponde, resumidamente, à perda do valor econômico dos ativos que têm por objeto bens físicos (tangíveis) sujeitos a desgastes por perda de utilidade, ou por uso, ou por ação da natureza ou mesmo por obsolescência. Contabilmente, é a alocação sistemática do valor depreciável de um ativo ao longo de sua vida útil (BULGARIM et al., 2011; FRANÇA, 2015).

Analisando o Balanço Patrimonial da entidade, foi verificado que não é demonstra- da a depreciação de forma correta, pois cada componente de um item do ativo imobilizado com custo significativo em relação ao custo total do item deve ser depreciado separadamente. A entidade demonstra o valor inicialmente reconhecido de um item do ativo imobilizado aos componentes significativos desse item e os deprecia separadamente.

\subsection{REAPRESENTAÇÃO DAS DE- MONSTRAÇÕES}

De acordo com o disposto na Estrutura Conceitual Básica - CPC 00 - para ser confiável, a informação deve representar fidedignamente as transações e outros acontecimentos que ela pretende representar. Assim, a representação da realidade econômica completa deve incluir toda a informação necessária para que o usuário compreenda o fenômeno sendo retratado, muito embora a representação fidedigna não traduza a exatidão em todos os aspectos.

A partir dos documentos coletados no estudo e por meio de simulações efetuadas, foram refeitos os demonstrativos da instituição a fim de demonstrar, reconhecendo os limites da pesquisa, os fatos que constavam a parte das demonstrações. 


\begin{tabular}{|c|c|}
\hline \multicolumn{2}{|c|}{ DEMONSTRATIVO DO RESULTADO DO PERÍODO - ANO DE 2015.} \\
\hline RECEITA OPERACIONAL & \\
\hline Com Restrição & $170.898,98$ \\
\hline Convênio CNAS Área da Assistência Social & $57.764,82$ \\
\hline Programa APAE Energia Área da assistência Social & $9.598,28$ \\
\hline Convênio Teste do Pezinho Área de Saúde & $2.495,00$ \\
\hline Receita com Doações de Alimentos - PREFEITURA & R\$ 9.840,88 \\
\hline Receita com Trabalho Voluntário & R\$ 91.200,00 \\
\hline Sem Restrição & 23.205,00 \\
\hline Receitas de Doações Área da Educação & $2.306,82$ \\
\hline Receitas de aluguel Área de Educação & $7.200,00$ \\
\hline Outras Receitas Área da Educação & $11.498,18$ \\
\hline Receita com Trabalho Voluntário & R\$ 2.200,00 \\
\hline Custos e Despesas Operacionais c/ Programas & $162.826,95$ \\
\hline (-) Despesa Geral na Área da Assistência Social & $59.187,75$ \\
\hline (-) Despesa Geral na Área da Educação & $2.165,27$ \\
\hline (-) Despesas Geral na Área da Saúde & 433,05 \\
\hline (-) Despesa com Professor Municipal & R\$ 91.200,00 \\
\hline (-) Despesa Suprimento Alimentação & R\$ 9.840,88 \\
\hline Resultado Bruto & 31.277,03 \\
\hline Despesas Operacionais & $48.677,60$ \\
\hline (-) Despesas c/ o Pessoal Área da Assistência Social & $27.423,19$ \\
\hline (-) Despesas c/ o Pessoal área da Educação & $13.944,36$ \\
\hline (-) Despesas c/ o Pessoal Área da Saúde & $5.110,05$ \\
\hline Despesa com Serviço de Pedreiro & R\$ 2.200,00 \\
\hline OPERAÇÕES DESCONTINUADAS (LÍQUIDO) & $-17.400,57$ \\
\hline DÉFICIT DO PERÍODO & $-17.400,57$ \\
\hline
\end{tabular}

Quadro 9 - Demonstração do Resultado do Período ajustado Fonte: dados da pesquisa (2016).

Foi identificada uma diferença no valor de $\mathrm{R} \$ 518,00$ entre o valor apurado na Demonstração do Resultado do Exercício e o valor transferido para o Balanço Patrimonial como Déficit do Exercício. Por não ter sido possível obter informações a respeito desta diferença, os pesquisadores realizaram o ajuste na conta de Déficit Acumulado, uma vez que o resultado do exercício deve ser integralmente transferido para o Patrimônio, a fim de demonstrar geração ou diminuição da riqueza econômica. Como o foco do estudo está limitado ao exercício de 2015, não foram analisados os exercícios anteriores.

Ainda em análise do Balanço Patrimonial, foi realizado um ajuste na evidenciação do Ativo Imobilizado, o qual constava na demonstração anterior evidenciado por seu valor contábil bruto, e, após feitos os ajustes, demonstra-se por seu valor contábil líquido. O Balanço Patrimonial ajustado pode ser conferido abaixo. 


\begin{tabular}{|c|c|c|c|}
\hline \multicolumn{2}{|l|}{ ATIVO } & \multicolumn{2}{|c|}{ PASSIVO } \\
\hline ATIVO CIRCULANTE & $\mathrm{R} \$ 2.238,48$ & $\begin{array}{l}\text { PASSIVO } \\
\text { CIRCULANTE }\end{array}$ & R\$ $1.717,84$ \\
\hline DISPONIBILIDADES & & $\begin{array}{l}\text { OBRIG. SOCIAIS E } \\
\text { TRABALHISTAS }\end{array}$ & \\
\hline Caixa Geral & & Inss a Recolher & $\mathrm{R} \$ 126,08$ \\
\hline Caixa Área da Assistência Social & $\mathrm{R} \$ 947,68$ & Fgts a Recolher & $\mathrm{R} \$ 126,08$ \\
\hline Banco Conta Aplicação & & Pis s/ Faturamento & $\mathrm{R} \$ 15,76$ \\
\hline Banco Área da Assistência Social & $\mathrm{R} \$ 1.290,80$ & Salários a Pagar & $\mathrm{R} \$ 1.449,92$ \\
\hline NÃO CIRCULANTE & R\$192.125,89 & NÃO CIRCULANTE & $\mathrm{R} \$ 17.013,78$ \\
\hline Subvenção Geral a Receber & & $\begin{array}{l}\text { SUBVENÇÕES } \\
\text { PÚBLICAS A } \\
\text { REALIZAR }\end{array}$ & \\
\hline $\begin{array}{l}\text { Sub. a Receber na Área da } \\
\text { Assistência Social }\end{array}$ & $\mathrm{R} \$ 17.013,78$ & $\begin{array}{l}\text { Sub. a realizar na área } \\
\text { da Assist. Social }\end{array}$ & $\mathrm{R} \$ 17.013,78$ \\
\hline IMOBILIZADO & R\$175.112,11 & & \\
\hline Imobilizado Área da Administração & $\mathrm{R} \$ 80.504,72$ & & \\
\hline Edificação & $\mathrm{R} \$ 79.619,17$ & & \\
\hline Móveis e Utensílios & $\mathrm{R} \$ 885,55$ & & \\
\hline Imobilizado Área da Saúde & $\mathrm{R} \$ 3.450,20$ & & \\
\hline Móveis e Utensílios & $\mathrm{R} \$ 1.278,30$ & $\begin{array}{l}\text { PATRIMÔNIO } \\
\text { SOCIAL LÍQUIDO }\end{array}$ & R\$ $175.632,75$ \\
\hline Aparelhos e Equipamentos & $\mathrm{R} \$ 2.171,90$ & Patrimônio Social & $\mathrm{R} \$ 205.535,99$ \\
\hline $\begin{array}{l}\text { Imobilizado Área da Assistência } \\
\text { Social }\end{array}$ & $\mathrm{R} \$ 137.088,03$ & Déficit do Exercício & $-\mathrm{R} \$ 17.400,57$ \\
\hline Móveis e Utensílios & $\mathrm{R} \$ 3.048,73$ & Déficit Acumulado & $-R \$ 12.502,67$ \\
\hline Aparelhos e Equipamentos & $\mathrm{R} \$ 16.039,30$ & & \\
\hline Veículos e Utilitários & $\mathrm{R} \$ 118.000,00$ & & \\
\hline Imobilizado Área da Educação & $\mathrm{R} \$ 8.970,53$ & & \\
\hline Móveis e Utensílios & $\mathrm{R} \$ 738,27$ & & \\
\hline Aparelhos e Equipamentos & $\mathrm{R} \$ 8.232,26$ & & \\
\hline \multicolumn{4}{|l|}{ Depreciação Acumuladas } \\
\hline (-) Depreciações Acumuladas & $-\mathrm{R} \$ 54.901,37$ & & \\
\hline TOTAL DO ATIVO & R\$194.364,37 & TOTAL DO PASSIVO & $\mathrm{R} \$ 194.364,37$ \\
\hline
\end{tabular}

Quadro 10 - Balanço Patrimonial ajustado

Fonte: dados da pesquisa (2016).

\section{CONSIDERAÇÕES FINAIS}

O objetivo central deste trabalho foi identificar se os processos contábeis da entidade estão alinhados às Normas Brasileiras de Contabilidade Aplicadas ao Terceiro Setor - ITG 2002. Por meio de um estudo de caso, foram realizadas entrevistas semiestruturadas, utilizando um questionário estruturado com perguntas fechadas e abertas, aplicadas aos gestores da entidade, com a finalidade de realizar interpretação e análise de dados utilizando descrições e narrativas.

Observou-se que a entidade só faz a pres- 
tação de contas dos recursos de convênio para a Controladoria Geral do Município mesmo porque, o não comprimento desta prestação acarreta automaticamente o cancelamento dos recursos recebidos, principal fonte de sustento da entidade; porém, foi possível verificar que a associação não realiza prestação de contas à sociedade, por não ser obrigada legalmente, demonstrando a grande dificuldade de operacionalização desse conceito ainda nos tempos atuais, conforme apontado por Hyndman e McKillop (2018). Provavelmente, um aumento da divulgação de suas ações e resultados promoveria um contato mais aproximado com a sociedade local, que reconhecendo trabalho desenvolvido pela entidade, se sentiria mais à vontade para doar e ajudar em seu desenvolvimento, conferindo maior legitimidade a suas ações.

Também foi possível verificar que, apesar de os gestores considerarem a contabilidade muito importante para a prestação de contas, não mantêm um controle rigoroso quanto à divulgação dessas informações e, dessa forma acabam por não utilizar todo o potencial informativo que os instrumentos contábeis podem oferecer à sociedade por meio da evidenciação, corroborando os estudos de Falconer e Vilela (2001) e Cruz (2010). Dessa forma, percebe-se que o grau de importância atribuído à prestação de contas e ao uso da contabilidade é pequeno, sendo usado cerimonialmente para o cumprimento de exigências legais, como forma de firmar novos convênios e acordos e para a manutenção dos já existentes com órgãos governamentais, em especial, com o município de Guanambi.

Em termos do nível de conhecimento e das habilidades dos gestores da instituição, ficou claro que os relatórios de cunho financeiros são os de maior entendimento dos administradores, a exemplo do livro caixa, enquanto que as demonstrações contábeis se apresentam em um grau de compreensão inferior, mas corroborando os trabalhos de Camargo (2001), Falconer e Vilela (2001), Milani Filho (2011) e Gollo, Schulz e Rosa (2014) sobre a baixa utilização dos relatórios financeiros para amparar suas decisões.

Os achados fornecem insights significa- tivos para o gerenciamento de entidades ligadas ao Terceiro Setor e ao uso da informação contábil na dinâmica de desempenho dessas organizações, tendo como referência um estudo de caso. Considerando que a informação ganha valor real ou percebido quando utilizada em processos de decisão correntes ou futuras, podendo alterar sua qualidade ou gerar redução de custos (SANTOS, 2000); uma possível implicação da falta de utilização da informação contábil no processo de gerenciamento da entidade é a existência de um deficiente modelo de gestão que possa nortear o planejamento e consequentemente a avaliação da importância das informações contábeis para sua gestão.

Entre as evidências obtidas, verificou-se que nem todas as demonstrações contábeis obrigatórias dispostas na ITG 2002 (R1) são elaboradas e algumas, ainda que analisadas superficialmente, apresentaram equívocos como o demonstrado na Demonstração do Resultado do Exercício e no Balanço Patrimonial. Constatou-se, ainda, inconsistência nos registros contábeis em relação às Receitas de Doações, Trabalhos Voluntários e Depreciação em que foram realizadas sugestões para que a contabilidade demonstre, de forma mais fidedigna, a situação patrimonial, financeira e econômica em conformidade com a norma vigente, resultado que coaduna com o resultado do trabalho realizado por Fagundes e Rodrigues (2017) para entidades gaúchas.

O estudo teve sua limitação em relação à aplicação de um único caso local, não podendo, assim, generalizar seus resultados a outras organizações; assim, recomenda-se a realização de outros estudos privilegiando aspectos não tratados neste trabalho, como: aplicar a um número maior de APAEs, abrangendo outras regiões do Estado e unidades da federação; aplicar tal estudo a outros grupos ligados ao Terceiro Setor, para analisar empiricamente o uso das Demonstrações Contábeis nos processos de gestão e decisão dessas entidades e sobre a sobre a qualidade das informações contábeis para essas entidades.

Pesquisas futuras podem olhar para os diversos contextos sociais para explorar seu potencial em entender o que direciona as percepções 
dos gestores desse tipo de entidade sobre a relevância dos informes contábeis em seus processos.

MANAGEMENT BEYOND PROFITS: ACCOUNTING CONTROL IN A NONPROFIT ENTITY

\begin{abstract}
Even with a social focus, the Third Sector has processes that need to be controlled and disseminated to its various stakeholders, and accounting is one of the instruments that contribute to positive actions in regard to society. The purpose of this article is to know how these entities are maintained, whether their records, control and accountability of their resources, while analyzing an institution as a case. Exploratory and descriptive research was conducted, as well as semi-structured interviews with the entity's administrators, and document content analysis of the organization. Although mentioned as important by managers, it was noted that they do not have full knowledge about the financial statements for the management of the entity. There were inconsistencies of some operations and restricted use of the statements, used ceremonially for legal requirements. It can be concluded that the financial reports are those of higher understanding of the managers, whereas the financial statements are presented in a lower degree of understanding, being despised, which implies the lack of use of accounting information in the management process of the entity.
\end{abstract}

Keywords: Management. Financial Statements. Third sector.

\section{GERENCIAMIENTO ADEMÁS DE LOS LUCROS: CONTROLE FINANCIERO EN UNA ENTIDAD SIN FINES LUCRATIVOS}

\section{RESUMEN}

Mismo vueltas para el social, empresas de Tercero Sector poseen procesos que precisan de controle y divulgación a sus diversos interesados, y la contabilidad es una de las herramientas que contribuyen para una acción positiva frente a sociedad. El objetivo del artículo es identificar se los procesos financieros de la entidad están aliados a las Normas Brasileñas de Contabilidad Aplicadas al Tercero Sector ITG 2002. Fue realizada pesquisa exploratoria y descriptiva a través de entrevista semiestructurada con los administradores de la organización, además de análisis de contenido de documentos de la organización. Mismo mencionado como importantes por los gestores, se observó que ellos no tienen conocimiento total sobre las demostraciones financieras en el gerenciamiento de la entidad. Quedaron evidenciadas inconsistencias de algunas operaciones y uso restricto de los demostrativos, usados ceremonialmente para exigencias legales. Se concluye que los informes de carácter financiero son los de mayor entendimiento de los administradores, en cuanto que las demostraciones financieras se presentan en un grado de comprensión inferior, siendo relegados, lo que implica la falta de utilización de la información contable en el proceso de gerenciamiento de la entidad.

Palabras-clave: Gestión. Demostrativos Contables. Tercero Sector.

\section{REFERÊNCIAS}

BEUREN, Ilse Maria (Org). Como elaborar trabalhos monográficos em contabilidade: teoria e prática. 3.ed. São Paulo: Atlas, 2006.

BEUREN, Ilse Maria; CORRÊA, Fabiana Sens. A Contabilidade no processo de gestão das APAES do Médio Vale do Itajaí. R. Cont. UFBA, v. 3, n. 3, p. 5-16, 2009.

BIES, Angela L. Evolution of Nonprofit Self-Regulation in Europe. Nonprofit and Voluntary SectorQuarterly, v.39,n. 6,p.1057-1086, 2010. Disponível em: <http://journals.sagepub. com/doi/abs/10.1177/0899764010371852>. Acesso em: 15 jun. 2017. 
BRYMAN, A. Social Research Methods. 4th ed. Oxford: Oxford University Press, 2012.

BULGARIM, Maria Clara Cavalcante et al. Caderno de Procedimentos aplicáveis à prestação de contas das entidades do Terceiro Setor (fundações). 2. ed. Brasília: Fundação Brasileira de Contabilidade, 2011. Disponível em: <http://www1.cfc.org.br/uparq/terceiro setor.pdf>. Acesso em: 14 fev. 2016.

CAMARGO, M. F. Gestão do Terceiro Setor no Brasil: estratégias de captação de recursos para organizações sem fins lucrativos. São Paulo: Futura, 2001.

CONSELHO FEDERAL DE CONTABILIDADE (CFC). ITG 2002 (R1). Entidades sem Finalidade de Lucros. 2015. Disponível em: $<$ http://www2.cfc.org.br/sisweb/sre/detalhes sre.aspx?Codigo=2015/ITG2002\%28R1\%29>. Acesso em: 14 fev. 2016.

CRESWELL, John W. Projeto de pesquisa: métodos qualitativo, quantitativo e misto; tradução Magda Lopes. 3. ed. Porto Alegre: ARTMED, 2007.

CRUZ, Cassia Vanessa Olak Alves. A relevância da informação contábil para os investidores sociais privados de entidades do Terceiro Setor no Brasil: uma investigação empírica. 2010. Tese (Doutorado em Controladoria e Contabilidade: Contabilidade) - Faculdade de Economia, Administração e Contabilidade, Universidade de São Paulo, São Paulo, 2010. Doi:10.11606/T.12.2010.tde-24062010104557. Acesso em: 15 jun. 2017.

DIMAGGIO, P.; POWELL, W. The Iron Cage Revisited: Institutional Isomorphism and Collective Rationality in Organizational Fields. American Sociological Review, v. 48, n. 2, p. 147-160, 1983. Disponível em: <http://www. jstor.org/stable/2095101>. Acesso em: 17 jun. 2017.
EASTERBY-SMITH， M.; THORPE， R.; JACKSON, P. R. Management research. 3th ed. London: SAGE Publications, 2008.

EISENHARDT, Kathleen M. Control: Organizational and Economic Approaches. Management Science, v. 31, n. 2, p. 134-149, 1985. Disponível em: <http://dx.doi.org/10.1287/ mnsc.31.2.134>. Acesso em: 17 jun. 2017.

FAGUNDES, Gabriela das Neves; RODRIGUES, Ana Tércia Lopes. Nível de conformidade das demonstrações contábeis das entidades gaúchas do terceiro setor aplicadas às normas brasileiras de contabilidade. 2017.32 f. TCC (Graduação) - Curso de Curso de Ciências Contábeis, Faculdade de Ciências Econômicas, Universidade Federal do Rio Grande do Sul, Rio Grande do Sul, 2017. Disponível em: $<$ https://lume.ufrgs.br/handle/10183/183001>. Acesso em: 15 nov. 2018.

FALCONER, A. P.; VILELA, R. Recursos privados para fins públicos: as grantmakers brasileiras. São Paulo: Fundação Peirópolis, 2001. Disponível em: <http://www.issuelab. org/resources/19203/19203.pdf>. Acesso em: 16 jun. 2017.

FAMA, Eugene F.; MICHAEL C. Jensen. Agency Problems and Residual Claims. The Journal of Law \& Economics, v. 26, n. 2, p. 327-349, 1983. Disponível em: <www.jstor. org/stable/725105>. Acesso em: 16 jun. 2017.

FERNANDES, Rubem César. Privado, porém público: o terceiro setor na América Latina. Rio de Janeiro: Relume Dumará, 1994.

FRANÇA, José Antônio de (Coord.). Manual de Procedimentos para o Terceiro Setor: aspectos de gestão e de contabilidade para entidades de interesse social. Brasília: CFC, 2015.

GOLLO, Vanderlei; SCHULZ, Sheila Jeane; ROSA, Fabricia Silva da. Evidenciação contábil em entidades brasileiras de terceiro setor: 
adequação às normas brasileiras de contabilidade. ConTexto, v. 14, n. 27, p. 104-116, 2014.

HYNDMAN, Noel; McKILLOP. Public services and charities: Accounting, accountability and governance at a time of change. The British Accounting Review, v. 50, p. 143-148, 2018. DOI: https://doi.org/10.1016/j.bar.2018.01.001

IBGE - INSTITUTO BRASILEIRO DE GEOGRAFIA E ESTATÍSTICA. IBGE - cidades @. Disponível em: $<$ https://cidades.ibge.gov. br/brasil/ba/guanambi/panorama $>$. Acesso em: 15 nov. 2018.

IPEA - INSTITUTO DE PESQUISA ECONÔMICA APLICADA. Mapa das Organizações da Sociedade Civil. Disponível em: $<$ https:// mapaosc.ipea.gov.br/>. Acesso em: 16 nov. 2018 .

LAWRENCE, Thomas B.; SUDDABY, Roy; LECA, Bernard (Ed.). Institutional work: Actors and agency in institutional studies of organizations. Cambridge: Cambridge university press, 2009.

MCCONVILLE, Danielle; CORDERY, Carolyn. Charity performance reporting, regulatory approaches and standard-setting. Journal Of Accounting And Public Policy, v. 37, n. 4, p. 300-314, jul. 2018.

MAÑAS, A. V.; MEDEIROS, E. C. E. Terceiro Setor: um estudo sobre a sua importância no processo de desenvolvimento sócio-econômico. Perspectivas em Gestão \& Conhecimento, v. 2, n. 2, p. 15-29, 2012. Disponível em: $<$ http:// basessibi.c3sl.ufpr.br/brapci/v/a/12290>. Acesso em: 10 mar. 2016.

MARTINS, Pablo Luiz et al. A Contabilidade do Terceiro Setor: o Caso Anália Franco. In: SIMPÓSIO DE EXCELÊNCIA EM GESTÃO E TECNOLOGIA, 8., 2011, Rio de Janeiro. Anais eletrônicos... Rio de Janeiro: Associação Educacional Dom Bosco, 2011. Disponível em:
$<$ http://www.cienciascontabeis.com.br/importancia-contabilidade-terceiro-setor/>. Acesso em: 24 mar. 2016.

MILANI FILHO, Marco Antônio F. Avaliação de Desempenho de Organizações Filantrópicas: uma abordagem quantitativa baseada na eficiência. Revista de Economia \& Relações Internacionais, v. 9, p. 101-120, 2011.

RESENDE, Tomás de Aquino et al. Roteiro do Terceiro Setor. Associações e Fundações: o que são como instituir e prestar contas. 3. ed. Belo Horizonte: Prax, 2006.

SANTOS, Roberto Vatan dos. Controladoria: uma introdução ao sistema de gestão econômica (GECON). São Paulo: Saraiva, 2000.

SILVA, Antônio Carlos Ribeiro da. Metodologia da pesquisa aplicada à contabilidade. São Paulo: Atlas, 2003.

SILVA, Cleyde Madeira et al. A Contabilidade Para Entidades Do Terceiro Setor. 2006. Disponível em: <http://sinescontabil.com.br/ monografias/artigos/terceiro_setor.htm $>$. Acesso em: 10 mar. 2016.

TRIVIÑOS, A. N. S. Introdução à pesquisa em ciências sociais: a pesquisa qualitativa em educação. São Paulo: Atlas, 1987.

YANG, Cherrie; NORTHCOTT, Deryl. Unveiling the role of identity accountability in shaping charity outcome measurement practices. The British Accounting Review, v. 50, n. 2, p. 214226, 2018. DOI: 10.1016/j.bar.2017.09.010 YIN, Robert K. Case study research: design and methods. 3th ed. London: SAGE Publications, 2003. 